\title{
Le sultan circassien Barqūq d'après les relations de voyage de trois pèlerins florentins (1384)
}

The Circassian Sultan Barqūq in the Travel's Reports of Three Florentine

Pilgrims (1384)

Il sultano circasso Barqūq secondo le relazioni di viaggio di tre pellegrini

fiorentini (1384)

Bernadette Martel-Thoumian

\section{OpenEdition}

\section{Journals}

Édition électronique

URL : http://journals.openedition.org/cei/3581

DOI : 10.4000/cei.3581

ISSN : 2260-779X

Éditeur

UGA Éditions/Université Grenoble Alpes

Édition imprimée

ISBN : 978-2-37747-023-5

ISSN : 1770-9571

\section{Référence électronique}

Bernadette Martel-Thoumian, «Le sultan circassien Barqūq d'après les relations de voyage de trois pèlerins florentins (1384) », Cahiers d'études italiennes [En ligne], 25 | 2017, mis en ligne le 10 octobre 2017, consulté le 27 mars 2021. URL : http://journals.openedition.org/cei/3581 ; DOI : https://doi.org/ 10.4000/cei.3581

Ce document a été généré automatiquement le 27 mars 2021. 


\title{
Le sultan circassien Barqūq d'après les relations de voyage de trois pèlerins florentins (1384)
}

\author{
The Circassian Sultan Barqūq in the Travel's Reports of Three Florentine \\ Pilgrims (1384) \\ Il sultano circasso Barqūq secondo le relazioni di viaggio di tre pellegrini \\ fiorentini (1384)
}

Bernadette Martel-Thoumian

1 Aux XIV et $\mathrm{XV}^{\mathrm{e}}$ siècles, les pèlerins occidentaux qui visitent les lieux saints de Palestine font souvent escale au Caire, la capitale de l'État mamelouk ${ }^{1}$. Ils pénètrent alors dans un monde bien différent des leurs, notamment parce que le sultan, généralement un esclave étranger converti à l'islam et éduqué au métier des armes, a peu de points communs avec un roi ou un empereur d'Occident.

2 Si les mœurs et les coutumes étonnent les pérégrins, voire les amusent, le détenteur du pouvoir attire leur attention et suscite leur curiosité. Les guides tentent d'assouvir leur intérêt en leur fournissant nombre d'explications sur les origines ethniques, le parcours, le mode de vie et évidemment la religion originelle du personnage. En octobre 1384, trois Florentins, Lionardo Frescobaldi, Simone Sigoli et Giorgio Gucci séjournent au Caire et font connaissance avec l'Orient. Si dans leurs relations de voyage respectives le sultan (il soldano) [Barqūq] provoque des commentaires, jamais ils ne le mentionnent nommément; il est vrai qu'ils n'ont eu l'opportunité ni de le rencontrer ni même de l'apercevoir de loin².

3 Les pèlerins ne parlant pas l'arabe, leur unique source d'informations reste leur interprète (il nostro turcimano) qui d'après Gucci « era uno viniziano rinegato, ed avea per moglie una figliuola d'uno nostro fiorentino rinegato ${ }^{3}$ ». Sigoli a rencontré, probablement lors de ses déambulations au Caire, un dénommé Simon de Crète, marchand vénitien chrétien installé dans la ville: "uno cristiano, il quale ha nome Simone di Candia, ch'era quivi per mercatanti $a^{4} »$. Ce personnage qu'il est le seul à mentionner a acquis sa 
confiance. Ainsi lorsqu'il relate le splendide cadeau envoyé par le gouverneur de Damas (il ammiraglio di Domasco) au sultan, il reproduit les dires de Simon de Crète dont la véridicité ne peut être remise en question, car il a assisté à l'événement: «quello cristiano di Candia che disse l'avea veduto [il s'agit du cadeau $]^{5} »$.

\section{Le sultan, un illustre anonyme...}

4 Tout voyageur évoque généralement le système politique de la région qu'il visite et les trois Florentins n'échappent pas à cette règle. Toutefois, ayant probablement à cœur de relayer les diverses informations que l'interprète lui a transmises, seul Sigoli consacre au souverain mamelouk un long passage, même si à l'instar de ses compatriotes, il ne le mentionne pas nommément. En effet, Sigoli l'identifie comme étant le sultan du moment "costui che oggi è soldano" $o^{6}$, tandis que Frescobaldi précise: "Equando giugnemo nel Cairo, aveva già regnato due anni $i^{7}$ » Cette dernière information est exacte, Barqūq étant arrivé au pouvoir en novembre 1382. Quant à Gucci, il se limite pour toute présentation à un " uno » méprisant, on reviendra sur ce point plus tard ${ }^{8}$.

5 Toutefois, comment interpréter cet anonymat récurrent? Les auteurs ont-ils oublié le nom du souverain ou est-ce son statut d'ex-esclave qui confine ce dernier à l'oubli nominal? Par ailleurs, les Florentins soulignent qu'il n'est pas né esclave, mais qu'il l'est devenu. « $F u$ venduto per schiavo quando era fanciullo a uno ammiraglio ${ }^{9}$ » écrit Frescobaldi, «fu ischiavo in Sorìa ${ }^{10} »$ note Sigoli, alors que Gucci laisse planer un léger doute en remarquant " uno che fu prima schiavo ${ }^{11}$ ».

6 Si Frescobaldi et Sigoli infligent le même traitement au calife (il califfo, alcaliffo) - c'est alors Al-Watīiq qui est en fonction -, Gucci omet le mot dans sa relation, à croire qu'il n'a jamais été prononcé devant lui. Par ailleurs, Sigoli renvoie de temps à autre son informateur à un semi-anonymat quand il l'appelle "quello cristiano di Candia [ce chrétien de Crète]» ou «quello mercatante di Candia [ce marchand de Crète] ${ }^{12}$ ». Cette pratique est d'autant plus curieuse que cet auteur mentionne Sariacusso/Syriāqūs, comme un des lieux de chasse du sultan ${ }^{13}$. Est-ce la proximité euphonique avec la ville de Syracuse qui a facilité sa mémorisation?

7 Toutefois, ces textes recèlent une autre curiosité, le terme mamlouk n'est jamais employé, que ce soit à propos des soldats, des émirs ou du sultan ${ }^{14}$. Or si Barqūq a été un esclave domestique ('abd) lors de son séjour en Crimée, il est arrivé en Égypte pour être vendu comme esclave militaire/mamlūk. La différence est de taille, car les mamelouks constituent une armée de métier originale. Vendus enfants ou adolescents au sultan et aux émirs mamelouks, ils sont convertis à l'islam et apprennent le métier des armes. Leur éducation terminée, ils retrouvent la liberté, l'esclavage n'est pour eux qu'un état transitoire. D’ailleurs Sigoli évoque l'affranchissement de Barqūq quand il signale « colui di cui egli era lo liberò ${ }^{15}$ ".

8 Frescobaldi est relativement bien renseigné sur l'itinéraire de Barqūq, sur son achat par l'émir (il ammiraglio) Yalbuğā Al-'Umarī Al-Hāasșakī dont il fut l'un des pages (paggio), sur son ascension sociale au cœur du système mamelouk jusqu'au grade de grand émir ( $f u$ grande ammiraglio $\left.{ }^{16} »\right)$. Même la brouille avec son compagnon d'armes (Husǔdōšs) Baraka ibn 'Abd Allāh Al-Ǧūbānī - les deux jeunes gens avaient été achetés par Yalbuḡā - est évoquée. L'auteur dénonce également la responsabilité de Barqūq dans l'assassinat de son ami en octobre 1380: «[...] e poi ordinò d'uccidere l'altro grande 
ammiraglio; e fatto che l'ebbe morire ${ }^{17}$. » Sigoli raconte lui aussi cet épisode tragique avec moult détails ${ }^{18}$.

9 Ces récits ressemblent étrangement à ceux des auteurs arabes qui font généralement débuter la vie de Barqūq avec son arrivée sur le sol égyptien. Les pèlerins ont donc adopté la version officielle qui circulait au Caire, faisant de Barqūq un homme sans passé. Pour avoir quelques informations sur son adolescence, il faut se tourner vers le marchand et interprète siennois, Bertrando de Mignanelli et vers le chroniqueur arabe Al-'Aynī. Tous les deux fournissent quelques éléments sur cette période même si leurs versions diffèrent.

En 1394, le sultan Barqūq qui se trouvait à Damas fit appel à Mignanelli qui y résidait ; ce dernier traduisit la lettre envoyée par le duc de Milan Gian Galeazzo Visconti. Il rédigea également la réponse du sultan à ce dernier ${ }^{19}$. Le Siennois a rédigé une monographie intitulée Ascensus Barcoch. Ce texte ne comprend aucune date et son contenu oscille pour reprendre l'expression de N. Mahmoud Helmy entre «biografia, novella e romanzo d'avventura ${ }^{20} »$. Par ailleurs, Mignanelli l'a rédigé en 1416, à la demande de ses amis alors qu'il assistait au concile de Constance, soit environ dix-sept ans après la mort du sultan survenue en $1399^{21}$.

11 Quant à Al-'Aynī (1361-1451), qui occupa sous Barqūq le poste de muhtasib («préfet des marchés $\left.{ }^{22} »\right)$, il est apparemment le seul auteur arabe à avoir osé démythifier le passé du souverain. On ignore qui lui a fourni les renseignements qu'il consigne dans la longue nécrologie qu'il lui consacre dans le 'Iqd al-ğumān fi tārì̈ ahl al-zamān lors de son décès en 1399 , cependant nul doute que sa connaissance de la langue turque lui a ouvert des portes ${ }^{23}$.

12 Néanmoins, le biographe et le chroniqueur s'accordent sur un point, le jeune Caucasien fut capturé, puis vendu comme esclave. Cette affirmation est plausible. Les marchands d'esclaves prisaient d'autant plus les jeunes gens originaires des contrées sous la domination de la Horde d'or qu'ils pouvaient les revendre très cher à Caffa ${ }^{24}$. Cependant, les deux auteurs divergent quand ils évoquent le métier du jeune Barqūq; Mignanelli en fait le gardien des cochons de son père, tandis qu'Al-'Aynī le décrit officiant comme garçon de bain dans un hammam.

13 Ainsi, si l'on suit Mignanelli, « Barqūq s'occupait des cochons de son père lorsqu'il a été capturé par des pirates qui l'ont vendu à un marchand d'esclaves, qui l'a par la suite revendu à l'émir Yalbuğà ${ }^{25} »$. Pour sa part Al-'Aynī écrit :

Il [Barqūq] [...] a été réduit en esclavage par un individu de Madīnat Qrim. C'était un beau jeune homme. Il est resté un certain temps chez un homme qui tenait un hammam. Il distribuait des serviettes à ceux qui entraient dans l'établissement, les gens affluaient autour de lui ${ }^{26}$.

14 Si d'après Mignanelli, le jeune Barqūq était porcher, on verra plus loin ce que cette information sous-entend, Al-'Aynī décrit un bel éphèbe (gulām) travaillant dans un hammam, en contact direct avec la clientèle masculine. En effet, la personne chargée de distribuer les serviettes se tenait à l'entrée de l'établissement. Les bains, ouverts jour et nuit, étaient selon les jours et les horaires réservés à un public masculin et faisaient office de lieux de rencontre. Par ailleurs, il était de notoriété publique que bien des garçons de bain s'y prostituaient. Le séduisant Barqūq focalisait derechef les regards masculins et son patron a sans doute mis à profit les atouts physiques de son employé pour faire prospérer son établissement ${ }^{27}$. 
Toutefois, le ḥammāmī (tenancier du hammam) décida un jour de se séparer de lui, et il le vendit à 'Uțān Al-Musāfir, un puissant marchand d'esclaves. Ayant dépassé la vingtaine, Barqūq n'attirait plus autant les regards ${ }^{28}$. De retour au Caire, Al-Musāfir proposa le jeune homme au grand émir Yalbugà̄ Al-‘Umarī Al-Hāșșakī. Ce transfert de maître devait radicalement changer la destinée du garçon de bain. Devenu mamelouk, puis grand émir, Barqūq parvint à accéder au trône sultanien ${ }^{29}$.

\section{... riche...}

Lorsqu'il se fut emparé du pouvoir, Barqūq s'installa comme ses prédécesseurs dans la citadelle (il castello) qui domine Le Caire. Cette construction initiée par Saladin en 1176-1177 fut terminée et aménagée par ses successeurs, puis investie par les mamelouks qui en firent à leur tour le siège de leur puissance. Juchée sur une éminence, sa masse imposante captait tous les regards. Frescobaldi ne résiste pas à l'envie d'en dire plus sur ce bâtiment auquel il attribue des origines quasi-mythiques: "Il suo castello è appunto dove fu quello di Faraone re d'Egitto e dove fu allattato Moisès. » Au cas où l'on viendrait à en douter, il ajoute «come dice la Bibbia ${ }^{30} »$. Pour sa part, Gucci précise que le castello donne sur une grande place (le Maydān), qu'il paraît très grand et [qu'il parait] être un bel édifice à l'intérieur (" pare grandissimo e bello edificio dentro »). Il note également que la Citadelle a de hauts murs percés de plusieurs portes, mais que la plus importante semble être celle qui donne sur la place. Les pèlerins n'ont pas accédé au bâtiment. Néanmoins, ils auraient pu y pénétrer s'ils avaient été munis d'une autorisation ${ }^{31}$.

Le sultan Barqūq était revenu la veille d'une partie de chasse de plusieurs jours lorsque les Florentins atteignirent Le Caire ( Il dì che giugnemo al Cairo tornava il soldano dalla caccia ed era stato più dì»). Si Frescobaldi s'étend peu sur le sujet se contentant de souligner le faste des chasses sultaniennes (" e aveano mille padiglioni, che mai non fu più ricca $\left.\cos ^{32} »\right)$, Sigoli semble sous le charme. Certes, les souverains et les nobles occidentaux s'adonnent à cette activité, mais si l'on en croit l'auteur, les chasses sultaniennes dépassent en splendeur ce que l'on peut voir ailleurs. Pour appuyer son assertion, il donne un exemple dans lequel l'emphase numérique l'emporte sur le descriptif. Dans ce compte rendu, tout est démesuré, aussi bien le nombre des participants que l'important matériel déployé à cette occasion. Les adjectifs gran et grande parfois au pluriel, parfois au superlatif (grandissima) ainsi que le mot quantità, ponctuent son discours. Le sultan est un homme très riche, il suffit de lire le récit de Sigoli dont on donne ici un résumé.

Quand le sultan va chasser à Syriāqūs, il emmène avec lui environ 100000 cavaliers/ centomila uomini a cavallo et plutôt plus que moins/e innanzi più che meno qui portent un grand nombre/grandissima quantità de gerfauts et de faucons pèlerins, de nombreux/grande quantità de braques et de lévriers. Et on amène pour le sultan un très grand/grandissimo pavillon, si grand que l'on a pas assez de cent chameaux pour le porter, parce qu'il est constitué de beaucoup de morceaux et de beaucoup de colonnes de bois/ «moltissimi pezzi e moltissime colonne di legname». Ce pavillon comprend nombre de pièces/gran quantità, si bien qu'on ignore où le sultan dort. Mais les émirs ont également leurs propres tentes en grand nombre/altra quantità di padiglioni, aussi le campement a-t-il l'allure d'une ville, avec ses artères et ses commerces $^{33}$. 

arrivé le 11 octobre 1384 au Caire a été dans l'impossibilité d'assister au départ et au retour de l'expédition qui s'était déroulée du $1^{\mathrm{er}}$ au 10 octobre ${ }^{34}$. Ce récit lui vient sans doute de Simon de Crète. L'armée et le harem étant de la partie, les expéditions en direction de Syriāqūs mobilisaient un grand nombre de personnes. C'est du moins ce qu'écrit Ibn Tağrī-Birdī le lundi $1^{\text {er }}$ octobre 1397. Ce type de déplacement n'est d'ailleurs pas présenté comme une chasse (șayd), mais comme un voyage périodique annuel (sarha 'alā l-āda fi l-kull sana), aussi le sultan fut-il de retour le 20 muharram $(13 \text { octobre })^{35}$. Un tel voyage impliquait le déploiement de l'important matériel décrit par Sigoli, même si le nombre des participants était certainement très inférieur à celui qu'il énonce. impressionné. Il donne du souverain un portrait physique flatteur, même s'il ne l'a jamais rencontré. En 1384, le sultan a environ 45 ans et c'est d'après lui, un très bel homme vigoureux ("è bellissimo uomo della persona e gagliardo ») et il est courtois autant que dire se peut ( $e$ cortese quanto dire si puot $e^{36} »$ ). Ce court descriptif laudatif n'est pas sans rappeler le héros du roman courtois. Si d'après les auteurs arabes, la civilité du sultan ne fut pas toujours de mise, son apparence flatteuse attira les regards jusqu'à sa mort. D'après Al-'Aynī, à la soixantaine, le sultan portait encore beau : «Il était d'une belle taille, avait de larges épaules, des bras musclés, une barbe fournie, des cheveux poivre et sel et un nez mince et bien délimitée ${ }^{37}$.»

Bel homme de commerce agréable, Barqūq entretenait à sa cour environ 6000 personnes (circa a seimile persone), enfin plutôt plus que moins (« innanzi più che meno »). Mais ce n'est pas tant le faste de la cour, Simon de Crète ne lui en ayant pas dit plus, que les pratiques vestimentaires de Barqūq qui étonnent Sigoli. En effet, le souverain revêt des vêtements de prix («robe di gran valore »), il en change trois fois par jour («si muta ogni dì tre volte ») et lorsqu'il les enlève, il les dépose dans une garde-robe et il ne les remet plus ( e come se le cava di dosso, sono messe in una camera e giammai non se le rimette più »). Cette information laisse probablement le Florentin sans voix, un tel luxe étant peu fréquent en Occident. Toutefois, ces habits seront à nouveau portés, le sultan les offrant à ses émirs, à ses favoris, voire à d'autres personnes (secrétaires, qadis, savants). Par ce geste, il distingue et honore ceux qui les reçoivent. En un mot, Sigoli est réellement impressionné par le mode de vie de Barqūq, en témoignent les expressions "magnificenza del soldano [la magnificence du sultan]» (à deux reprises) et "sua grandezza [sa grandeur $]^{38} »$.

21 La polygamie étant admise par l'islam, Sigoli aborde ensuite ce chapitre. Bel homme riche, le sultan a sept épouses et bien d'autres femmes encore sur la terre (« il soldano ha sette mogli e anche tiene altre femmine per la terra »). L'auteur précise que les sept épouses sont «ses épouses principales [ma pure queste sette sono les sue principali $]^{39}$ ». Cette affirmation est reprise par Gucci qui l'assortit toutefois du commentaire suivant, faisant remarquer que cette pratique est légale : "che almeno conviene che n'abbi sette per loro costituzioni ${ }^{40}$ ». Or le Coran limite le nombre légal d'épouses à quatre ${ }^{41}$. Quant aux autres femmes évoquées, ce sont probablement des concubines serviles, originaires de différentes contrées, en particulier des régions turcophones.

Toutefois, la mention de sept épouses interpelle, car les sources arabes n'en mentionnent en 1384 que deux. Barqūq épousa la fille [anonyme] de l'émir Taštamur en 1380 et Fāṭima, fille de l'émir Manğak Al-Yūsufī en $1384^{42}$. Mignanelli note qu'il 
convola avec la mère du sultan Al-Ṣaliḥ Al-Ḥāğğḡi, veuve du sultan Al-Ašraf Šatbān probablement en $1381^{43}$ et Al-Maqrīzī signale une concubine turque, Ardū, mère d'un fils prénommé Muhammad né en $1380^{44}$. L'information de Sigoli soulève la question de l'écriture de sa relation ${ }^{45}$, car par la suite, Barqūq se marie effectivement avec au moins six autres femmes : Hāğir, fille de l'émir Manklī Bugiā Al-Šamsī, la fille [anonyme] de l'architecte Šihāb al-dīn Al-Ṭūlūnī, Ḥāğğ Malik, fille de Muḥammad Al-Bașrī, Qunuqbāy, fille de 'Abd Allāh, Šīīn Al-Rūmiyya, fille de 'Abd Allāh ainsi que Tandū, fille de Ḥusayn ibn Uways ${ }^{46}$.

Cinq de ces unions sont politiques. Les mariages avec les filles des émirs Taštamur, Manğak Al-Yūsufī et Manklī Buğā Al-Šamsī lui permirent de resserrer les liens avec certains de ses pairs, celui avec Bagaded, veuve d'Al-Ašraf Ša'bān lui donna le statut de " père » du sultan Al-Ḥāğğî âgé de onze ans et facilita son accession au trône, enfin celui avec Tandū, fille de l'émir ğalāyiride Hụusayn ibn Uways fut également stratégique $^{47}$. Quoi qu'il en soit, ce nombre d'épouses suscite la question du logement, aussi Sigoli disserte-t-il sur le sujet. Il note que chacune dispose d'une chambre à coucher et que lorsqu'elles se déplacent avec leurs nombreuses suivantes ("grande quantità di donzelle»), elles sont chacune gardées par quatre eunuques («quattro schiavi castrati ») qui les suivent dans tous leurs déplacements ${ }^{48}$.

Ces divers thèmes sont toutefois peu fédérateurs. En effet, si Sigoli les développe, Frescobaldi ne fait qu'aborder celui de la chasse que Gucci ignore. Par contre, ils s'intéressent tous les trois au passé religieux de Barqūq et à sa prise de pouvoir.

\section{... et renégat}

En effet, s'il est un sujet qui fait l'unanimité dans les trois récits c'est celui de la religion originelle du Circassien Barqūq. Les auteurs ont cependant du mal à s'accorder sur son origine géographique, même s'ils le disent Grec. Ainsi d'après Sigoli il serait un « cristiano rinnegato di nazione greca ${ }^{49}$ » et Frescobaldi abonde dans ce sens quand il écrit " cristiano di Grecia ${ }^{50}$ ", mais peut-être Barqūq est-il, comme le prétend Gucci, un " greco cristiano di Carcascia del Mare Maggiore ${ }^{51} »$. On peut certes s'interroger sur l'expression "nation grecque ", mais pour les auteurs, cela signifie que le personnage n'est pas un Latin. Que Barqūq ait pu être chrétien est une éventualité, car selon Al-Qalqašandī, il y avait en Circassie de nombreuses personnes qui avaient adopté ce monothéisme ${ }^{52}$.

Par ailleurs, les Florentins opèrent une étroite corrélation entre christianisme et esclavage. Pour eux, il ne fait aucun doute que c'est sa condition de chrétien qui lui a valu la macule servile. Ainsi Gucci note-t-il : "[...] fu prima schiavo e greco cristiano di Carcascia del Mare Maggiore ${ }^{53}$. " Mignanelli est le seul à évoquer sa religion originelle par le biais de son métier, en effet en faisant du jeune Barqūq un porcher, il le place de facto parmi les chrétiens en vertu de l'interdit alimentaire se rapportant au cochon, qui ne peut être consommé ni même élevé par les musulmans ${ }^{54}$. Toutefois, cette information figurant uniquement chez Mignanelli, comment l'interpréter? D'abord est-elle véridique? De qui l'auteur la tient-il, du sultan, de son entourage? Quoi qu'il en soit, elle ne semble pas être parvenue aux oreilles des voyageurs.

27 Il est donc difficile de trancher, même si les pèlerins semblent convaincus en leur for intérieur et clament à l'unisson que Barqūq est un rinnegato. Toutefois, compte tenu du multi-confessionnalisme en Circassie où des musulmans, des chrétiens, des juifs et des païens se côtoyaient, il est également envisageable que Barqūq, membre de la tribu 
circassienne des Kasā, ait été polythéiste. Néanmoins, quelle qu'ait été la religion originelle de Barqūq, les Florentins ont compris l'enjeu politique qu'elle représentait dans l'État mamelouk. Les populations égyptienne et syrienne étant majoritairement musulmanes, le souverain ne pouvait appartenir à une autre confession. La conversion apparait donc comme un passage obligé pour tout individu convoitant le pouvoir.

Évoquer la religion, c'est également évoquer ses desservants, or l'islam n'a pas de clergé comparable à celui qui officie en Occident et en Orient. Il n'y a donc pas de hiérarchie religieuse et pas davantage d'ordre monastique. Le calife abbasside en résidence au Caire même s'il est l'amir al-mu'minin (l'émir des croyants) ne détient pas à proprement parler une fonction religieuse à ce moment-là. Toutefois, si les mamelouks l'ont cantonné à un rôle de figurant, il n'en reste pas moins une autorité morale.

Les auteurs le mettent en scène lors de l'accession au trône de Barqūq. On l'a dit précédemment, les pèlerins sont bien renseignés sur les principales étapes de la vie du converti Barqūq. Ils savent également que tout nouveau souverain doit prêter serment, et que celui qui officie lors cette cérémonie n'est autre que le calife. Toutefois, comment évoquer cet événement dans une relation de voyage destinée à un public occidental ? Frescobaldi et Sigoli comparent le calife au pape, «il califfo, come tu dicessi il papa » d'après Frescobaldi ${ }^{55}$, «[...] dell' alcaliffo loro, cioè il papa al nostro modo » selon Sigoli56.

Certes le raccourci est un peu osé, car des papes ont eu plus de liberté et de pouvoir que les Abbassides du Caire. Après la prise de Bagdad par les Mongols en 1258, sa mise à sac et l'exécution du calife Al-Musta'ṣim, les mamelouks ont accueilli ses parents ayant réchappé des massacres avec une arrière-pensée, légitimer leur accession au pouvoir. Ainsi le calife abbasside Al-Mustanșir fit-il prêter serment à Baybars en 1261. Par la suite, aucun sultan ne put se targuer d'être légitime si le calife ne l'avait pas investi de l'autorité sur les pays d'Islam lors d'une cérémonie, la bay'a, ce que rappelle Sigoli quand il note: "Ora, prima che uno sia confermato soldano, si conviene ch'egli abbia le voci dell'alcaliffo loro ${ }^{57}$. "

31 L'accession au pouvoir de Barqūq est à nouveau l'occasion de revenir sur la religion originelle de ce dernier. En effet, d'après Frescobaldi le calife aurait refusé de lui faire prêter serment sous prétexte que son père était chrétien, et que le nouveau souverain devait être musulman et fils de musulman. "Disse il califfo non lo poteva fare, perocché la loro legge vuole che chi è soldano sia saracino e figliuolo di saracino e che il suo padre era cristiano ${ }^{58}$. " Cette information est erronée, car le calife Al-Mutawakkil a présidé la prestation de serment de Barqūq le 26 novembre $1382^{59}$. En effet, ce n'est pas parce que les quatorze descendants du sultan Qalā'ūn, décédé en 1290, ont occupé le trône jusqu'en 1382 qu'une loi successorale a vu le jour ${ }^{60}$. Par ailleurs, si pour accéder au pouvoir le sultan devait être musulman, la religion de ses ascendants ne constitua jamais un critère discriminant. Al-Mutawakkil ne fut donc pas jeté en prison pour avoir refusé d'appliquer une loi qui n'existait pas et ne fut pas davantage, ainsi que le prétend Sigoli, remplacé par un de ses parents. L'auteur se trompe quand il écrit : «[...] questi ch'è oggi soldano fece pigliare l'alcaliffo e fecelo mettere in prigione, e poi ne fece uno a suo modo ${ }^{61}$. " Si le calife fut destitué en août 1383, c'est parce qu'il était suspecté de tremper dans un complot contre le sultan Barqū $q^{62}$. Ce dernier nommera un frère de l'ex-calife Al-Muta'șim qui prendra le nom d'Al-Wațīq, avant de réintégrer Al-Mutawakkil dans la fonction en $1389^{63}$. Gucci fait brièvement allusion à ce conflit et n'éprouve nullement le besoin d'épiloguer quand 
il mentionne: «E sono $i$ detti soldani per tutto ubiditi nel temporale e spirituale sanza contrario, se il contrario non procede dalla sua corte ${ }^{64}$. "

Frescobaldi évoque également l'arrivée en Égypte d'Anaș, le père de Barqūq, faisant du fils un ignoble personnage prêt à tout pour s'emparer du trône.

[Barqūq] ordinò con certi cattivi cristiani di Grecia che ingannevolmente gli menarono il padre, al quale per forza fece rinegare la fede del Cristo e circonciderlo secondo la loro legge; di che in brieve tempo tra per la pena e per lo dolore si mori ${ }^{65}$.

Ce passage horrifiant comporte quelques erreurs. Si Anaș est bien arrivé en Égypte le 5 mars 1381, il est difficile de déterminer le rôle joué par d'éventuels chrétiens, car c'est le marchand d'esclaves 'Uțmān Al-Musāfir qui avait amené Barqūq en Égypte en 1362-1363 qui se chargea de lui. Sa conversion à l'islam est évoquée par les auteurs arabes, mais elle ne semble pas avoir été contrainte. Toutefois, il est difficile de se prononcer sur ce point ainsi que sur sa religion originelle. Anaș était d'après les sources arabes octogénaire ou nonagénaire, il décéda le 2 janvier 1382, soit quelques mois avant l'avènement de son fils. Exhiber son père qu'il accueillit en grande pompe permit à Barqūq de se distinguer de ses congénères qui ne pouvaient agir de même. Ces derniers étaient considérés comme nés de pères inconnus et désignés comme ibn 'Abd Allāh (fils de l'esclave de Dieu), alors que lui était le fils d'Anaș (ibn Anaș) que tous avaient pu voir ${ }^{66}$.

Quant à Sigoli, il ne s'étend pas sur le sujet, motivant le refus du calife par cette expression lapidaire "perroché la signoria non doveva essere sua ${ }^{67}$ ». En effet, "la seigneurie ne devait pas être sienne » et Barqūq a usurpé le trône, mais en agissant ainsi, il n'innovait pas, il marchait dans les pas de ses illustres prédécesseurs Baybars (1260-1277) et Qalā'ūn (1280-1290). La relation de Sigoli comporte également quelques inexactitudes. En 1377, Barqūq appartient au groupe de conjurés qui assassinent le sultan Al-Ašraf Ša'bān qui détenait le pouvoir depuis 1363. Al-Manșūr 'Alī, le fils et successeur de ce dernier, n'a que sept ans, mais il promeut Barqūq au poste enviable de maréchal des armées (atābak al-'asākir), lui mettant ainsi le pied à l'étrier. Al-Manșūr 'Alī décède de la peste en $1381^{68}$. Hésitant à interrompre brutalement la dynastie qalā'ūnide, Barqūq préfère favoriser l'accession au pouvoir d'un frère du défunt, AlȘālih Al-Ḥāğğ̄̃ âgé de onze ans. Il le dépose l'année suivante et s'empare du pouvoir.

Si l'on excepte l'assassinat de Ša'bān, et encore Barqūq n'est-il qu'un des conjurés, le futur sultan n'a pas de sang régicide sur les mains. Si 'Alī décède de la peste, Al-Hâăğḡi est destitué, mais il revient sur le trône lorsque Barqūq le perd brièvement de 1389 à 1390. Le mamelouk a donc su patiemment attendre son heure, sachant pertinemment qu'il devait rallier suffisamment d'appuis pour finaliser ses ambitions. Les émirs ont, ainsi que le note Mignanelli, préféré un homme mature issu de leurs rangs à un enfant ${ }^{69}$. Barqūq n'a donc pas eu besoin d'agir selon les dires de Sigoli : « [Barqūq] si fece pigliare i figliuoli che rimasono dell'altro soldano [?] e fecegli mettere in prigione, e simile tutti $i$ loro parenti di ceppo ${ }^{70}$.»

Quand à Gucci, il a une autre approche de l'accession au pouvoir de Barqūq. En peu de mots il résume et analyse finement la situation, il lui reproche de s'être emparé du pouvoir par la force, la duperie et la trahison, et d'avoir fait exécuter ceux dont il doutait, en particulier des émirs importants. « [Barqūq] avea presa tra per forza e inganni e tradimenti la detta signoria del soldano [...] ed avea fatto morire grandi signori ed amiragli e potenti, di cui dubitava. " Il dénonce également sa gestion politique, n'hésitant pas à utiliser une figure dérivative lorsqu'il l'accuse de se comporter en tyran gouvernant 
tyranniquement la dite seigneurie (!) : « e per forza e come tiranno tirannescamente detta signoria tenea ${ }^{71} »$. L'auteur juge sans doute ce comportement méprisable et estime qu'il n'y a rien de plus à dire sur l'homme. Il ne sera dans sa relation ni question du père du sultan ni du calife et encore moins des fastes de la cour sultanienne.

\section{Conclusion}

Lionardo Frescobaldi, Simone Sigoli et Giorgio Gucci sont relativement bien renseignés sur le système mamelouk, tant sur les modes d'accès au pouvoir que sur le rôle légitimant du calife. Toutefois, leur séjour au Caire ne constitue qu'une des étapes de leur voyage en Terre sainte. Il suffit pour s'en convaincre de lire leurs relations respectives. Des trois Florentins, Sigoli est le plus disert sur son séjour dans la ville. Il est fasciné par le spectacle qui s'offre à lui, mais également par ce que lui raconte le marchand Simon de Crète sur le puissant du jour, le sultan Barqūq.

Si contrairement à ses deux concitoyens, Sigoli, esprit curieux, note ses impressions, il n'est pas pour autant un naïf. En effet, il ne se laisse pas complètement abuser. Après s'être extasié sur le faste sultanien auquel il consacre quelques passages, il n'hésite pas à dénoncer la brutalité des mœurs politiques. Certes, des erreurs émaillent son récit, mais étant peu familier du système mamelouk et de sa complexité, il a eu du mal à assimiler et surtout à mémoriser toutes les informations émanant de Simon de Crète. Toutefois, le portrait qu'il dresse du sultan est réaliste et sa description des pratiques de cour bien menée.

Par ailleurs, les auteurs opèrent un tri parmi les choses vues et entendues, aussi leurs Viaggi diffèrent-ils. Si Frescobaldi éprouve le besoin de montrer sa culture par le biais d'une incursion dans le passé en évoquant Pharaon et Moïse, Gucci se limite à l'essentiel politique. Quant à Sigoli, se voulant rapporteur, il consigne consciencieusement ce qu'il a vu et entendu. Toutefois, et c'est sans doute un des aspects novateurs de son Viaggio, il n'essaie pas de tout expliquer à l'aune des pratiques occidentales tel qu'on le verra fréquemment $a u x^{e}$ siècle. Il n'empêche, les trois Florentins voient en Barqūq un greco rinnegato alors que rien ne vient étayer leurs dires et que la période des croisades est révolue ${ }^{72}$.

\section{BIBLIOGRAPHIE}

\section{Sources arabes}

AL-'AyNī, 'Iqd al-ğumān fì tārīH ahl al-zamān, Islām Yuša' Bīnū (éd.), Amman, Dār al-Yazurī, 2012.

AL-MAQRĪZĪ, Kitāb al-sulūk li-ma'rifat duwal al-mulūk, Muḥammad Muṣtafā Ziyadā et Sa'īd 'Abd alFattāḥ Ašūr (éds), Le Caire, Dār al-kutub, 1957-1973, 4 vol.

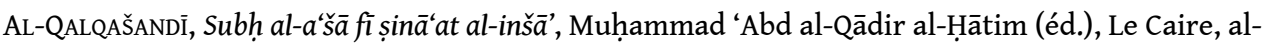
Mu'assasa al-mișriyya al-‘āmma li l-ta'lîf wa l-tarğama wa l-țibā‘a wa l-našr, 1963, 14 vol. 
AL-ṢAYRAFī, Nuzhat al-nufūs wa l-abdān fì tawārīH al-zamān, Ḥasan Ḥabašā (éd.), Le Caire, Dār alkutub, 1970-1994, 4 vol.

GAULMIER Jean, La Zubda kachf al-mamālik de Khalīl az-Zāhirī, traduction inédite de Jean-Michel de Venture de Paradis, Beyrouth, IFD, 1950.

IBN TAĠRĪ-BIRDĪ, Al-Manhal al-șāfi wa l-mustawfi ba'd al-wāfi, Muhammad Muhammad Amīn (éd.), Le Caire, Dār al-kutub, 1956-2009, 13 vol.

IBN TAĠRİ-BIRDĪ, Al-Nuğūm al-zāhira fī mulūk al-Miṣr wa l-Qāhira, Muḥammad Ḥusayn Šams al-dīn (éd.), Beyrouth, Dār al-kutub al-'ilmiyya, 1992, 16 vol.

\section{Sources italiennes}

FiscHeL William, «Ascensus Barcoch. A Latin Biography of the Mamlūk Sultan Barqūq (D. 1399) Written by B. de Mignanelli in 1416: Rendered into English with an Introduction and a Commentary ", Arabica, t. VI, 1959, fasc. I, p. 57-74, fasc. II, p. 152-172.

Gucci Giorgio, « Viaggio ai Luoghi Santi », dans Antonio Lanza et Marcellina Troncarelli (éds), Pellegrini scrittori. Viaggiatori toscani del Trecento in Terrasanta, Florence, Ponte alle Grazie, 1990, p. 257-312.

IORGA Nicolae, Notes et extraits pour servir l'histoire des croisades au XVe siècle, Paris, Ernest Leroux, 1899, traduction partielle en français d'Ascensus Barcoch, appendice II, p. 529-542.

LANZA Antonio et TRONCARELli Marcellina (éds), Pellegrini scrittori. Viaggiatori toscani del Trecento in Terrasanta, Florence, Ponte alle Grazie, 1990.

Mahmoud Helmy Nelly, Tra Siena, l'Oriente et la Curia. Beltramo di Leonardo Mignanelli e le sue opere, Rome, Instituto Storico Italiano per il Medio Evo, « Nuovi Studi Storici, 91 », 2013, texte latin d'Ascensus Barcoch, p. 341-353.

PiLoTi Emmanuel, Traité sur le passage en Terre sainte, 1420, édité par Pierre-Herman Dopp, Louvain, E. Nauwelaerts, 1958.

SIGoli Simone, Viaggio al monte Sinai, dans Antonio Lanza et Marcellina Troncarelli (éds), Pellegrini scrittori. Viaggiatori toscani del Trecento in Terrasanta, Florence, Ponte alle Grazie, 1990, p. 217-255.

\section{Ouvrages et articles}

'ABD AL-RĀZIQ Ahmad, La femme au temps des Mamlouks en Égypte, Le Caire, IFAO, 1973.

AMIR-Mozzzi Mohammad Ali (dir.), « Polygamie », dans Dictionnaire historique du Coran, Paris, Bouquins, Robert Lafon, 2007, p. 679-682.

Assouly Olivier, Les nourritures divines. Essai sur les interdits alimentaires, Lonrai, Babel, 2013.

BENCHEIKH Jamal Eddine, « Poésies bachiques d'Abū Nuwās. Thèmes et personnages », Bulletin d'études orientales, vol. XVIII, 1964, p. 7-84.

BouHDIBA Abdelwahab, La sexualité en Islam, Paris, PUF, 1975.

GARCIN Jean-Claude, « Histoire, opposition politique et piétisme traditionaliste dans le Husn almuḥāạara de Suyūṭī », Annales islamologiques, vol. 7, 1967, p. 33-89.

GREKOV Boris et IAKOUBOVSKI Aleksandr, La Horde d'or et la Russie. La domination tatare aux XIII et XIV ${ }^{e}$ siècles de la mer Jaune à la mer Noire, Paris, Payot, 1961. 
MARÇAIS William, « Al-‘Aynī », dans Encyclopédie de l'Islam, 2e éd., Leyden, Brill, 1960, vol. I, p. 814.

MARTEL-THOUMIAN Bernadette, «Plaisirs illicites et châtiments dans les sources mamloukes, fin $\mathrm{IX}^{\mathrm{e}} / \mathrm{XV}^{\mathrm{e}}$-début $\mathrm{X}^{\mathrm{e}} / \mathrm{XVI}^{\mathrm{e}}$ siècle », Annales islamologiques, vol. 39, 2005, p. 275-323.

MARTEL-THOUMIAN Bernadette, Délinquance et ordre social. L'État mamlouk syro-égyptien face au crime à la fin du IXe $/ X v^{e}$ siècle, Bordeaux, Ausonius, 2012.

MARTEL-Thoumian Bernadette, « Dans le regard de l'autre. Pèlerins et mamlouks à travers l'étude de quelques récits de voyage (fin XIVe-début XVI ${ }^{\mathrm{e}}$ siècle) ", Journal asiatique, vol. 302, nº 2, 2014, p. 439-455.

MARTEL-Thoumian Bernadette, « Portrait du sultan mamlouk Barqūq (784-791/1382-1389 ; 792-801/1390-1399) en chrétien renégat ", dans Contacts and Interaction, Actes du XXVII ${ }^{\mathrm{e}}$ Congrès de l'UEAI (juin 2014), Leuven, Peters, « Orientalia Lovaniensia Analecta, 254 », 2017, p. 323-333.

MARTEL-THOUMIAN Bernadette, « Ascensus Barcoch (1416) : une hagiographie laïque ? ", dans Actes du 24e CHESFAME (Leuven, 18-20 mai 2016), à paraître.

ONimus Clément, Les émirs dans le sultanat mamelouk sous les sultans Barqūq et Farağ (784-815/1382-1412). Restauration sultanienne et conflits émiraux, thèse soutenue à l'EPHE, Paris, 2013, tome III, Annexes, en cours de publication.

SOURDEL Dominique et SOURDEL Janine, « Bienséance », dans Dictionnaire historique de l'islam, Paris, PUF, 1996, p. 159.

SOURDEL Dominique et SOURDEL Janine, « Hisba », dans Dictionnaire historique de l'islam, Paris, PUF, 1996, p. 349-350.

SOURDEL Dominique et SOURDEL Janine, « Jalaïrides ou Djalāyirides », dans Dictionnaire historique de l'islam, Paris, PUF, 1996, p. 424-425.

SUBLET Jacqueline, Le voile du nom. Essai sur le nom propre arabe, Paris, PUF, 1991.

VASARY Istvàn, « Orthodox Christian Qumans and Tatars of the Crimea in the 13th-14th

Centuries ", dans Turks, Tatars and Russians of Crimea in the 13th-16th Centuries (Variorum Reprints), Ashgate, 2007, p. 260-271.

WENSINCK Arent Jan, « Khitān », dans Encyclopédie de l'Islam, 2e éd., Leyden, Brill, 1979, vol. V, p. 20-23.

\section{NOTES}

1. Le sultanat mamelouk né en 1250 a succombé sous les coups des Ottomans, lorsque ces derniers conquirent la Syrie en 1516, puis l'Égypte en 1517. Les mamelouks étaient achetés enfants ou adolescents, réduits en esclavage et convertis à l'islam. Leur éducation militaire terminée, ils étaient émancipés. Le sultan n'était que le primus inter pares, le premier des pairs, le premier d'entre eux. En 1261, le sultan mamelouk Baybars accueillit au Caire Ahmad ibn Al-Ẓāhir Muhammad, un descendant des Abbassides de Bagdad, après la mise à sac de la ville par les Mongols. Devenu calife sous le nom d'Al-Mustanșir, il n'eut aucun pouvoir politique et ses successeurs furent également réduits à faire de la figuration, sauf Al-Musta'īn billāh qui fut pendant quelques mois calife-sultan en 1412.

2. Pour les biographies respectives des trois pèlerins, voir A. Lanza et M. Troncarelli (éd.), Pellegrini scrittori. Viaggiatori toscani del Trecento in Terrasanta, Florence, Ponte alle Grazie, 1990, p. 24-25. 
3. «L'interprète était un Vénitien renégat, marié avec la fille d'un Florentin renégat. » (G. Gucci, «Viaggio ai Luoghi Santi », dans A. Lanza et M. Troncarelli (éd.), Pellegrini scrittori, ouvr. cité, p. 270.) Frescobaldi et Sigoli rapportent également que l'homme est un Vénitien renégat. Ils le qualifient de grand truchement (gran turcimano), toutefois Frescobaldi précise qu'il occupe cette fonction auprès du sultan (gran turcimano del soldano): cf. L. Frescobaldi, «Viaggio in Terrasanta ", dans Pellegrini scrittori, ouvr. cité, p. 181, 187 ; S. Sigoli, « Viaggio al monte Sinai », dans A. Lanza et M. Troncarelli (éd.), Pellegrini scrittori, ouvr. cité, p. 225. À noter que les auteurs ont des différences orthographiques, Frescobaldi écrit rinnegato et turcimano tandis que Gucci consigne rinegato et turcimanno.

4. S. Sigoli, « Viaggio al monte Sinai », art. cité, p. 230.

5. Ibid., p. 231. S. Sigoli traduit émir par ammiraglio tandis que L. Frescobaldi, soucieux de donner un équivalent au lectorat occidental, précise « uno ammiraglio, come tu dicessi capitano di guerra [un émir, comme tu dirais (un) capitaine de guerre]» ("Viaggio in Terrasanta », art. cité, p. 181). Gucci orthographie amiraglio ("Viaggio ai Luoghi Santi », art. cité, p. 266). La venue du gouverneur de Damas, l'émir Sayf al-dīn Baydamur al-Hुawārizmī est mentionnée par Al-Maqrīzī, Kitāb al-sulūk li-ma'rifat duwal al-mulūk, Le Caire, 1957-1973, vol. III/2, p. 513-514.

6. S. Sigoli, « Viaggio al monte Sinai », art. cité, p. 232.

7. «Quand nous parvînmes au Caire, il avait déjà régné deux ans. » (L. Frescobaldi, «Viaggio in Terrasanta ", art. cité, p. 181.)

8. G. Gucci, « Viaggio ai Luoghi Santi », art. cité, p. 266.

9. «Il fut vendu comme esclave quand il était enfant à un émir.» (L. Frescobaldi, «Viaggio in Terrasanta », art. cité, p. 181.)

10. « Il fut esclave en Syrie. » (S. Sigoli, « Viaggio al monte Sinai », art. cité, p. 232.)

11. « Un qui fut d'abord esclave. » (G. Gucci, « Viaggio ai Luoghi Santi », art. cité, p. 266.)

12. S. Sigoli, «Viaggio al monte Sinai », art. cité, p. 231, 234.

13. Syriāqūs est une localité située à une vingtaine de kilomètres au nord du Caire.

14. G. Gucci, lorsqu'il évoque les jeunes eunuques du harem, les décrit comme étant «servigiali giovani sanati, ch'egli chiamano nemaluchi [de jeunes serviteurs castrés qu'ils appellent des eunuques] ». Le mot nemaluchi peut prêter à confusion, car en italien mamelouk se dit mamelucco. M. Troncarelli donne comme équivalent eunuchi («Viaggio ai Luoghi Santi», art. cité, p. 270, n. 4).

15. « Celui qui le possédait le libéra. » (S. Sigoli, « Viaggio al monte Sinai », art. cité, p. 232.)

16. Le système mamelouk comprend quatre grades émiraux, l'émirat de cinq, l'émirat de dix, l'émirat de quarante et l'émirat de cent. Ces grades sont attribués par le sultan en fonction des états de service des impétrants et de son bon vouloir. En théorie ils sont étroitement corrélés à la possession de mamelouks, ainsi l'émir de cinq doit entretenir au minimum cinq mamelouks personnels, l'émir de dix, dix mamelouks personnels et ainsi de suite. Barqūq ayant obtenu l'émirat de cent, le grade le plus élevé, Frescobaldi le qualifie de "grande ammiraglio ». Le mot paggio renvoie au terme arabe Hāssșaki.

17. «[...] et puis il [Barqūq] a ordonné de tuer l'autre grand émir [Baraka] et ce dernier fut mis à mort. » (L. Frescobaldi, « Viaggio in Terrasanta », art. cité, p. 181.)

18. S. Sigoli est également bien informé sur la rivalité entre Barqūq et Baraka et il relate son issue fatale («Viaggio al monte Sinai», art. cité, p. 233). Voir également la version donnée par B. de Mignanelli dans N. Iorga, Notes et extraits pour servir l'histoire des croisades au XV siècle, Paris, Ernest Leroux, 1899, appendice II, p. 533 ; W. Fischel, « Ascensus Barcoch. A Latin Biography of the Mamlūk Sultan Barqūq (D. 1399) Written by B. de Mignanelli in 1416: Rendered into English with an Introduction and a Commentary ", Arabica, t. VI, 1959, fasc. I, p. 68-71 et N. Mahmoud Helmy, Tra Siena, l'Oriente et la Curia. Beltramo di Leonardo Mignanelli e le sue opere, Rome, Instituto Storico Italiano per il Medio Evo, "Nuovi Studi Storici, 91 », 2013, texte latin, p. 345-349. B. MartelThoumian, «Ascensus Barcoch (1416) : une hagiographie laïque?», dans Actes du $24^{e}$ CHESFAME 
(Leuven, 18-20 mai 2016), à paraître. Pour Baraka ibn 'Abd Allāh Al-Ǧūbānī, cf. Ibn Tag̉rī-Birdī, AlManhal al-șāfì wa l-mustawfï ba‘d al-wāfi, Le Caire, Dār al-kutub, 1984, vol. 3, p. 351-355.

19. Gian Galeazzo Visconti demandait à Barqūq la permission de restaurer la basilique de Bethléem ainsi que la protection des frères du Mont Sion à Jérusalem.

20. «Biographie, nouvelle et roman d'aventure" (N. Mahmoud Helmy, Tra Siena, l'Oriente et la Curia, ouvr. cité, p. 189 et suiv.).

21. Pour la biographie de B. de Mignanelli, cf. N. Iorga, Notes et extraits, ouvr. cité, p. 529-532 ; W. Fischel, « Ascensus Barcoch », art. cité, Introduction, p. 57-63 et N. Mahmoud Helmy, Tra Siena, l'Oriente et la Curia, ouvr. cité, p. 3-87.

22. Le muhtasib exerçait ses fonctions dans divers domaines. Il était chargé de la surveillance des souqs, de veiller au respect de la morale, de contrôler l'exercice du culte, de s'assurer que les esclaves n'étaient pas brutalisés, que les maîtres d'école respectaient les programmes et ne maltraitaient pas leurs élèves... Pour de plus amples informations, cf. D. et J. Sourdel, « Ḥisba », dans Dictionnaire historique de l'islam, Paris, 1996, p. 349-350.

23. Al-'Aynī, 'Iqd al-ğumān fì tārīH ahl al-zamān, Islām Yuša' Bīnū (éd.), Amman, Dār al-Yazurī, 2012, p. 101-113 ; W. Marçais, "Al-'Aynī », dans Encyclopédie de l’Islam, 2e éd., Leyden, Brill, 1960, vol. I, p. 814. B. Martel-Thoumian, «Portrait du sultan mamlouk Barqūq (784-791/1382-1389; 792-801/1390-1399) en chrétien renégat ", dans Contacts and Interaction, Actes du XXVII ${ }^{e}$ Congrès de l'UEAI (juin 2014), Leuven, Peters, « Orientalia Lovaniensia Analecta, 254 », 2017, « Un passé peu avouable ? », p. 326-329 et Ead., Délinquance et ordre social. L'État mamlouk syro-égyptien face au crime à la fin $\mathrm{du}_{\mathrm{IX}} \mathrm{e} / \mathrm{XV}^{e}$ siècle, Bordeaux, Ausonius, 2012, p. 53 et p. 146.

24. E. Piloti, Traité sur le passage en Terre sainte, 1420, édité par P. H. Dopp, Louvain, E. Nauwelaerts, 1958, p. 53-54.

25. N. Iorga, Notes et extraits, ouvr. cité, p. 532 ; W. Fischel, « Ascensus Barcoch », art. cité, p. 64, ce dernier indique qu'il gardait des cochons sans plus de précision et N. Mahmoud Helmy, Tra Siena, l'Oriente et la Curia, ouvr. cité, texte latin, p. 341.

26. Al-'Aynī, 'Iqd al-ğumān, ouvr. cité, p. 101. On ignore si le bain se trouvait à Madīnat Qrim, mais c'est une éventualité. Madīnat Qrim, aujourd'hui Stary-Krym, a probablement été fondée dans la deuxième moitié du XIII ${ }^{\mathrm{e}}$ siècle lorsque la Crimée était occupée par les Mongols. La ville était située à $15 \mathrm{~km}$ à l'ouest de Feodosia (cf. B. Grekov et A. Iakoubovski, La Horde d'or et la Russie. La domination tatare aux XIII et XIV siècles de la mer Jaune à la mer Noire, Paris, Payot, 1961, p. 135). AlȘayrafī note "qu'un individu l'a réduit en esclavage à Madīnat Qrim alors qu'il était un adolescent imberbe " (Nuzhat al-nufūs wa l-abdān fì tawārīH al-zamān, Ḥasan Ḥabašāà (éd.), Le Caire, Dār al-kutub, 1970, vol. 1, p. 497).

27. A. Bouhdiba, La sexualité en Islam, Paris, PUF, 1975 et plus précisément «Hammam et sexualité », p. 197-213.

28. Barqūq avait alors 23 ans, un autre chapitre de sa vie s'ouvrait. En effet, l'éphèbe (íulām) ou l'échanson (sāqī) décrit par Abū Nuwās est «un adolescent, sinon un enfant, mince, svelte et souple. Il est coquet, séduisant, gracieux comme une fille [...] Un léger vice de prononciation trahit son origine étrangère et ajoute à son charme " (J. Bencheikh, « Poésies bachiques d'Abū Nuwās. Thèmes et personnages ", Bulletin d'études orientales, vol. XVIII, 1964, p. 62-63).

29. Si pour Mignanelli Barqūq aurait été l'objet de deux transactions, pour Al-‘Aynī il aurait été la propriété de trois personnes.

30. "Son château est précisément là où se trouvait celui de Pharaon, roi d'Égypte et où Moïse fut allaité [...] comme le dit la Bible.» (L. Frescobaldi, "Viaggio in Terrasanta », art. cité, p. 181.) Quant à Gucci, il note que «Bambillonia è la città antica donde fu Faraone [Babylone est la ville antique où résida Pharaon] » («Viaggio ai Luoghi Santi », art. cité, p. 265).

31. «Vedemo il castello del soldano [...] Non vi fummo dentro, perché per gli Cristiani non vi s'usa entrare, se non con licenza. » (G. Gucci, « Viaggio ai Luoghi Santi », art. cité, p. 270.) 
32. «Il y avait mille tentes, une chose plus riche jamais ne fut.» (L. Frecobaldi, «Viaggio in Terrasanta ", art. cité, p. 181.)

33. S. Sigoli, «Viaggio al monte Sinai », art. cité, p. 231.

34. Al-Maqrīzī, Kitāb al-sulūk li-márifat duwal al-mulūk, ouvr. cité, p. 520. Les Florentins sont arrivés tard le 10 octobre et ne sont entrés dans la ville que le lendemain matin: cf. S. Sigoli, «Viaggio al monte Sinai », art. cité, p. 224 ; L. Frescobaldi, «Viaggio in Terrasanta », art. cité, p. 180 ; G. Gucci, « Viaggio ai Luoghi Santi », art. cité, p. 265.

35. Ibn Tag̉rī-Birdī, Al-Nuğūm al-zāhira fì mulūk al-Mișr wa l-Qāhira, Muhammad Ḥusayn Šams aldīn (éd.), Beyrouth, Dār al-kutub al-'ilmiyya, 1992, vol. 12, p. 58.

36. S. Sigoli, « Viaggio al monte Sinai », art. cité, p. 230.

37. Al-'Aynī, 'Iqd al-ğumān, ouvr. cité, p. 105.

38. S. Sigoli, «Viaggio al monte Sinai », art. cité, p. 230. "Le sultan, ses épouses, sa famille, la domesticité masculine et féminine à leur service, des hommes d'armes chargés de sa sécurité, des émirs, son conseil ainsi que beaucoup d'autres personnes résident dans la Citadelle. » (G. Gucci, «Viaggio ai Luoghi Santi », art. cité, p. 270.)

39. S. Sigoli, «Viaggio al monte Sinai », art. cité, p. 230.

40. G. Gucci, « Viaggio ai Luoghi Santi », art. cité, p. 270.

41. «Épousez deux, trois ou quatre, parmi les femmes qui vous plaisent, mais si vous craignez de ne pas être justes avec chacune d'entre elles, alors une seule (Coran, IV/3).» (M. A. Amir Moezzi (dir.), « Polygamie », dans Dictionnaire historique du Coran, Paris, 2007, p. 679-682.)

42. Al-Maqrīzī, Kitāb al-sulūk li-ma'rifat duwal al-mulūk, ouvr. cité, vol. III/1, p. 377 ; vol. III/2, p. 513 ; et A. Abd al-Raziq, La femme au temps des Mamlouks en Égypte, Le Caire, IFAO, 1973, p. 277, n. 49.

43. N. Iorga, Notes et extraits, ouvr. cité, p. 533 ; W. Fischel, «Ascensus Barcoch ", art. cité, fasc. I, p. 73 et N. Mahmoud Helmy, Tra Siena, l'Oriente et la Curia, ouvr. cité, texte latin, p. 351. Toutefois, cette femme prénommée Bagaded n'est pas signalée en tant qu'épouse de Barqūq dans le TārīH alduwal wa l-mulūk d'Ibn al-Furāt, Beyrouth, 1936-1938, vol. IX/I, p. 48. Voir également A. Abd alRaziq, La femme au temps des Mamlouks en Égypte, ouvr. cité, p. 272, n. 16.

44. Al-Maqrīzī, Kitāb al-sulūk li-ma'rifat duwal al-mulūk, ouvr. cité, vol. III/1, p. 380.

45. En effet, car un seul des Viaggi est daté, celui de Gucci qui l'a terminé le 4 octobre 1390.

46. A. Abd al-Raziq, La femme au temps des Mamlouks en Égypte, ouvr. cité, Hāğir, p. 285, n. 96 ; Bint Šihāb al-dīn Al-Ṭūlūnī, p. 282, n. 82 ; Ḥāğğ Malik, p. 285, n. 95 ; Qunuqbāy, p. 290, n. 129 ; Šīrīn, p. 294, n. 149 et Tandū, p. 297, n.166. C. Onimus répertorie 16 femmes dans Les émirs dans le sultanat mamelouk sous les sultans Barqūq et Farağ (784-815/1382-1412). Restauration sultanienne et conflits émiraux, thèse soutenue à l'EPHE, Paris, 2013, tome III, Annexes, p. 743, en cours de publication.

47. Husayn ibn Uways, le père de Tandū fut l'émir des Ğalāyirides (1374-1383). La dynastie d'origine mongole des Ğalāyirides (1336-1432) est née du démembrement de l'État des Ilkhanides, elle essaya un temps de dominer l'Irak et ses routes caravanières (Bagdad fut abandonnée définitivement en 1412). Cf. D. et J. Sourdel, "Jalaïrides ou Djalāyirides », dans Dictionnaire historique de l'islam, ouvr. cité, p. 424-425.

48. S. Sigoli, « Viaggio al monte Sinai », art. cité, p. 230-231 ; G. Gucci, « Viaggio ai Luoghi Santi », art. cité, p. 270. Pour le harem et son fonctionnement sous les mamelouks, cf. J. Gaulmier, La Zubda kachf al-mamālik de Khalì az-Zāhirī, traduction inédite de Venture de Paradis, Beyrouth, IFD, 1950, p. 203-205.

49. S. Sigoli, «Viaggio al monte Sinai », art. cité, p. 230. Il reprend cette affirmation plus loin : « greco ed è cristiano rinnegato » (p. 232).

50. L. Frescobaldi, « Viaggio in Terrasanta », art. cité, p. 181. 
51. G. Gucci, «Viaggio ai Luoghi Santi », art. cité, p. 266. Migannelli écrit également que Barqūq est Circassien : cf. N. Iorga, Notes et extraits, ouvr. cité, p. 532 ; W. Fischel, « Ascensus Barcoch», art. cité, fasc. I, p. 64 et N. Mahmoud Helmy, Tra Siena, l'Oriente et la Curia, ouvr. cité, texte latin, p. 341.

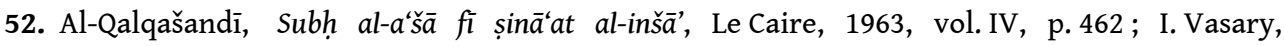
"Orthodox Christian Qumans and Tatars of the Crimea in the 13th-14th Centuries ", dans Turks, Tatars and Russians of Crimea in the 13th-16th Centuries (Variorum Reprints), Ashgate, 2007, p. 260-271 et B. Martel-Thoumian, "Portrait du sultan mamlouk Barqūq", art. cité, "Une identité ethnico-religieuse floue », p. 324-326.

53. «Il fut d'abord esclave et Grec de Circassie, de la mer Majeure. » (G. Gucci, « Viaggio ai Luoghi Santi », art. cité, p. 236.)

54. Cf. O. Assouly, Les nourritures divines. Essai sur les interdits alimentaires, Lonrai, Babel, 2013, p. 69.

55. «Le calife, comme tu dirais le pape. » (L. Frescobaldi, «Viaggio in Terrasanta », art. cité, p. 181.)

56. «Leur calife, c'est-à-dire le pape à notre mode. » (S. Sigoli, "Viaggio al monte Sinai », art. cité, p. 232.) B. de Mignanelli abonde dans le même sens : cf. W. Fischel, « Ascensus Barcoch", art. cité, fasc. II, p. 159 et N. Mahmoud Helmy, Tra Siena, l'Oriente et la Curia, ouvr. cité, texte latin, p. 367.

57. «Avant que quelqu'un soit confirmé sultan, il faut qu'il ait les voix de leur calife.» (S. Sigoli, "Viaggio al monte Sinai », art. cité, p. 232.) Dans la pratique, les émirs élisaient par acclamations un des leurs, le calife validait ce choix en l'investissant solennellement sultan lors de la bay'a.

58. «Le calife avait dit qu'il ne pouvait pas le confirmer parce que la loi veut que celui qui est sultan soit sarrasin et fils de sarrasin alors que son père était chrétien. » (L. Frescobaldi, « Viaggio in Terrasanta ", art. cité, p. 181.)

59. Al-Maqrīzī, Kitāb al-sulūk li-ma'rifat duwal al-mulūk, ouvr. cité, vol. III/2, p. 477.

60. Quant à la religion du père du futur sultan, Frescobaldi fait référence aux Qalā'ūnides qui étaient tous par leur naissance nés musulmans, étant fils, petits-fils et arrières petits-fils de Qalā'ūn. Cette dynastie constitue un anachronisme politique dans l'histoire de l'État mamelouk.

61. "Celui qui est aujourd'hui sultan [Barqūq] a fait arrêter le calife [Al-Mutawakkil], il l'a fait jeter en prison, puis il l'a remplacé par une personne qui lui convenait [Al-Wațīq]. » (S. Sigoli, «Viaggio al monte Sinai », art. cité, p. 232.) B. de Mignanelli donne la même version, mais il ajoute que Barqūq a agressé physiquement le calife en posant son épée sur le ventre de ce dernier : cf. N. Iorga, Notes et extraits, ouvr. cité, p. 534 ; W. Fischel, « Ascensus Barcoch », art. cité, fasc. I, p. 74 et N. Mahmoud Helmy, Tra Siena, l'Oriente et la Curia, ouvr. cité, texte latin, p. 353.

62. Al-Maqrīzī, Kitāb al-sulūk li-ma'rifat duwal al-mulūk, ouvr. cité, vol. III/2, p. 493-496.

63. Ibid., p. 603-604. J-C. Garcin, « Histoire, opposition politique et piétisme traditionaliste dans le Ḥusn al-muhạạdara de Suyūṭī », Annales islamologiques, vol. 7, 1967, p. 59-60. Lorsqu'Al-Watīi décède en 1386, son frère Al-Muta'șim est de nouveau calife jusqu'en 1389, date à laquelle Barqūq le démet et rappelle Al-Mutawakkil.

64. «Tous les sultans détiennent le temporel et le spirituel sans opposition, car il n'y a aucune opposition à leur cour. » (G. Gucci, « Viaggio ai Luoghi Santi », art. cité, p. 266.)

65. «Barqūq avait convaincu des mauvais chrétiens de Grèce de lui amener son père par la ruse. Il contraignit ce dernier à renoncer à la foi du Christ et il le fit circoncire selon leur loi ; si bien que le père mourut peu de temps après de peine et de douleur.» (L. Frescobaldi, «Viaggio in Terrasanta ", art. cité, p. 181.) Toutefois, la circoncision ne figure pas dans le Coran, mais dans les hadiths, et si elle est recommandée par le droit, seule l'école chaféite en fait en obligation formelle. Cf. D. et J. Sourdel, « Bienséance », dans Dictionnaire historique de l'islam, ouvr. cité, p. 159 et A. J. Wensinck, «Khitān », dans Encyclopédie de l'Islam, $2^{\mathrm{e}}$ éd., Leyden, Brill, 1979, vol. V, p. 20-23. 
66. Ainsi le fondateur de la dynastie qalā'ūnide, Qalā'ūn figure-t-il dans les chroniques, à l'instar de tous les sultans issus de l'esclavage, en tant que Qalā'ūn ibn 'Abd Allāh. «C'est donc un père fictif et musulman qu'ont les mamelouks importés enfants, ils sont donc dit fils de l'esclave de Dieu, ils ne gardent de leur lointaine patrie que le ism/nom reçu à leur naissance. " Cette remarque s'applique également aux femmes qui sont dites bint 'Abd Allāh (fille de l'esclave de Dieu). Cf. J. Sublet, Le voile du nom. Essai sur le nom propre arabe, Paris, PUF, 1991, p. 30.

67. S. Sigoli, « Viaggio al monte Sinai », art. cité, p. 232.

68. Ibid. Il est curieux que Sigoli évoque une grande maladie alors que le sultan est mort de la peste : «Il soldano venne in malattia, e brevemente la malattia sua fu sì grande ch'e' se ne morì [Le sultan tomba malade, et rapidement sa maladie fut si grande qu'il en mourut]. »

69. N. Iorga, Notes et extraits, p. 536; W. Fischel, « Ascensus Barcoch», art. cité, fasc. I, p. 73-74 et N. Mahmoud Helmy, Tra Siena, l'Oriente et la Curia, ouvr. cité, texte latin, p.352-353. On peut toutefois douter que Barqūq se soit fait prier pour accepter le trône ainsi que le note B. de Mignanelli.

70. « Il fit arrêter les fils de l'autre sultan, il les emprisonna et agit de la même manière avec tous leurs parents. » (S. Sigoli, « Viaggio al monte Sinai », art. cité, p. 232.)

71. G. Gucci, « Viaggio ai Luoghi Santi », art. cité, p. 266.

72. B. Martel-Thoumian, «Dans le regard de l'autre. Pèlerins et mamlouks à travers l'étude de quelques récits de voyage (fin XIV -début $\mathrm{XVI}^{\mathrm{e}}$ siècle)», Journal asiatique, vol. 302, $\mathrm{n}^{\circ} 2,2014$, p. 439-455.

\section{RÉSUMÉS}

En 1384, Lionardo Frescobaldi, Giorgio Gucci et Simone Sigoli, trois pèlerins florentins en route pour la Terre sainte font escale au Caire. De retour, chacun rédige une relation de voyage dans laquelle il relate les étonnantes coutumes des autochtones et les pratiques à la cour du sultan. L'État mamelouk est un monde surprenant, ceux qui détiennent le pouvoir, le sultan circassien Barqūq et les émirs, sont tous des militaires, mais surtout d'anciens esclaves étrangers convertis à l'islam. Mais qui est ce Barqūq qui gouverne l'Égypte et la Syrie depuis 1384, comment est-il parvenu à s'emparer du pouvoir ? Son cheminement vers la gloire retient leur attention et attise leur curiosité.

In 1384, Lionardo Frescobaldi, Giorgio Gucci and Simone Sigoli, three Florentine pilgrims on the road for the Holy Land spend few days in Cairo. Returning to their country, each write a Viaggio, where he related informations about the disconcerting customs of the natives and the the manners of the sultan's court. The Mamluk state is an ashtonished world, those who govern it, the Circassian sultan Barqūq and the emirs, are all military men, foreigners and ancient slaves converted to Islam. But who is this Barqūq who rules Egypt and Syria since 1382, how he manages to obtain full power? The Barqūq's road to glory preoccupies their attention and stirs up their curiosity.

Nel 1384, Lionardo Frescobaldi, Giorgio Gucci e Simone Sigoli, tre pellegrini fiorentini in cammino per la Terra Santa, fanno scalo al Cairo. Di ritorno in patria, ognuno di loro scrive una relazione di viaggio nella quale riferisce gli strabilianti costumi degli autoctoni e le pratiche alla corte del Sultano. Lo stato Mammalucco è un mondo sorprendente; i detentori del potere, il 
sultano circasso Barqūq e gli Emiri sono tutti militari, ma soprattutto ex schiavi stranieri convertiti all'Islam. Ma chi è quel Barqūq, dal 1384 a capo dell'Egitto e della Siria? e com'è riuscito ad impadronirsi del potere? La sua ascensione verso la gloria attira l'attenzione dei tre pellegrini e ne suscita la curiosità.

\section{INDEX}

Mots-clés : Barqūq, Lionardo Frescobaldi, Giorgio Gucci, Simone Sigoli, Le Caire, Al-Mutawakkil, Circassie, sultan, calife, chrétien renégat

Keywords : Barqūq, Lionardo Frescobaldi, Giorgio Gucci, Simone Sigoli, Le Caire, Al-Mutawakkil, Circassian Mamluk, sultan, caliph, Christian renegade

Parole chiave : Barqūq, Lionardo Frescobaldi, Giorgio Gucci, Simone Sigoli, il Cairo,

Al-Mutawakkil, Circassia, sultano, califfo, cristiano rinnegato

\section{AUTEUR}

\section{BERNADETTE MARTEL-THOUMIAN}

Université Grenoble Alpes 